\title{
Comparison of the effects of intravenous metoclopramide and ondansetron on prevention of nausea and vomiting after cesarean section.
}

\author{
Roghaiyeh Afsargharehbagh ${ }^{1}$, Saeed Mosaed ${ }^{2}$, Aliakbar Nasiri ${ }^{3}$, Mahdi Afshari ${ }^{*}$, Mahmood \\ Moosazadeh $^{5}$ \\ ${ }^{1}$ Department of Cardiology, Shohada Hospital, Urmia University of Medical Sciences, Urmia, Iran \\ ${ }^{2}$ School of Medicine, Zabol University of Medical Sciences, Zabol, Iran \\ ${ }^{3}$ Department of Anesthesiology, Urmia University of Medical Sciences, Urmia, Iran \\ ${ }^{4}$ Department of Community Medicine, Zabol University of Medical Sciences, Zabol, Iran \\ ${ }^{5}$ Health Sciences Research Center, Addiction Institute, Mazandaran University of Medical Science, Sari, Iran
}

\begin{abstract}
Background: Nausea and vomiting, after pain, is the most common adverse effect of cesarean section, such that it is reported in more than $66 \%$ of the patients undergoing cesarean section delivery under spinal anesthesia. There are several treatment choices for this problem, including injection of metoclopramide and ondansetron. This study aimed to compare the antiemetic efficacy of these two medications.

Methods: This double-blind, interventional study was conducted on 120 women undergoing cesarean section at Amir-Al Momenin Hospital, Zabol, Iran. The patients were randomly assigned to metoclopramide $(10 \mathrm{mg})$ and ondansetron $(4 \mathrm{mg})$ groups. The rate of nausea and vomiting was assessed in both groups immediately after cesarean section and every $6 \mathrm{~h}$ until $24 \mathrm{~h}$ after the operation. To analyze the data, Chi-squared test, McNemar's test, paired t-test, and Wilcoxon signed-rank test were run, using SPSS version 21 software.

Results: In total, the mean age of the participants was $30.41 \pm 8.22 \mathrm{y}$. The frequency rates of nausea and vomiting in the ondansetron group at $0,6,12$, and 24 hours after the operation were $36.7 \%, 35.0 \%$, $16.7 \%, 3.3 \%$ respectively. The corresponding figures for metoclopramide group were $28.3 \%, 21.7 \%$, $18.3 \%$, and $10.0 \%$ respectively.

Conclusion: Our study showed that ondansetron does not have any superiority to metoclopramide in terms of reducing post-cesarean nausea/vomiting. To confirm our results, further longitudinal studies with larger sample sizes are recommended.
\end{abstract}

Keywords: Ondansetron, Metoclopramide, Cesarean section.

Accepted on June 07, 2018

\section{Introduction}

Cesarean section is one of the most prevalent surgical procedures among women, conducting during the lack of progress in labor and some other indications. Pain, nausea and vomiting are the most common adverse effects of surgery, which are reported in more than $66 \%$ of patients undergoing cesarean section under spinal anesthesia [1]. These side effects are problematic and can delay discharge from recovery room and hospital and cause electrolyte imbalance, dehydration, force bleeding in sutures, esophageal rupture and increased prevalence of aspiration [2-4].

The risk factors for Postoperative Nausea and Vomiting (PONV) include female gender, no history of smoking, history of nausea and vomiting after surgery, motor disorders, migraine, young age, past history of drug abuse, general anesthesia, use of nitrous oxide, physical condition of the patient, post-operative hypotension as well as surgical duration and type of surgery (gynecological and abdominal) [1,5].

Ondansetron is the most common used 5-HT3 antagonist, which is of great importance for prevention of nausea and vomiting after chemotherapy or surgery. This antiemetic medicine exerts its effect through inhibition of the 5-HT3 peripheral receptors of postrema and chemoreceptor trigger zone. However, it mostly acts through inhibition of 5-HT3 peripheral receptors and vagal and spinal nerve terminals. Metoclopramide is an inhibiting dopaminergic medication classified as antiemetic which postpones the emptying of the 
digestive tract and stimulates bowel movement. Furthermore, since metoclopramide enhances the esophageal sphincter resting pressure, it can limit reflux of the gastric contents to the esophagus through broadening the range of the esophageal contractions [6-8].

Zahedi et al. compared the effects of metoclopramide and ondansetron and found that metoclopramide is a more effective antiemetic medication [9]. Norouzi showed effective role of ondansetron on controlling the nausea/vomiting after cesarean section $[10,11]$. In contrast to the results reported by Zahedi et al., Shende reported similar effects of both drugs in preventing nausea/vomiting while Suwannarurk et al. found better antiemetic effects for ondansetron $[12,13]$.

Although Pan demonstrated that ondansetron is more effective in controlling nausea during and post-cesarean section, it is not different from metoclopramide with respect to inhibiting vomiting [14].

There are some discrepancies regarding the findings of the previous studies on the effectiveness of ondansetron and metoclopramide for management of post-operative nausea and vomiting. Accordingly, we carried out this study to investigate the effects of these two medications for the treatment of such complications after cesarean section.

\section{Materials and Methods}

This clinical trial was performed on women aged 18-40 y referring to Amir-Al Momenin Hospital of Zabol, Iran. A total of 120 women, who were candidates for elective cesarean section, were assigned to ondansetron and metoclopramide ( $n=60$ in each group) groups by simple random sampling method.

The inclusion criteria comprised of singleton pregnancy, American Society of Anaesthesiologists (ASA) class I or II, and contraindication for spinal anesthesia. Moreover, the exclusion criteria were past history of severe PONV, history of severe motion sickness, history of drug abuse, pregnancy hypertension, consumption of antiemetic drugs one week before the operation, fasting for less than $6 \mathrm{~h}$, and preeclampsia.

Before conducting the study, we obtained approval of the Research Committee of Zabol University of Medical Sciences (Ethical code number: zbmu.1.REC.1395.88). Also this study approved in Iranian registry of clinical trial (IRCT20170502033762N2). Furthermore, the objectives of the study were explained to the patients, and written informed consent form was completed. Before spinal anesthesia, all the patients received 500 cc Ringer's lactate solution. Bupivacaine anesthetic solution T-T4 was employed for achieving anesthesia level of $12.5 \mathrm{mg}$. In addition, $3 \mathrm{l} / \mathrm{min}$ of oxygen was administered to the patients through nasal catheter.

We considered hypotension as more than $20 \%$ reduction from the baseline or decrease of systolic blood pressure to less than $90 \mathrm{mmHg}$, which was managed through administering $10 \mathrm{mg}$ of Ringer's lactate and ephedrine. To prevent aortocaval compression, we placed the patients on their left side. Immediately after clamping the umbilical cord, all the patients received either drug intravenously during two minutes.

As antiemetic medication, we gave $4 \mathrm{mg}$ of ondansetron to patients of the first group, while the second group received 10 $\mathrm{mg}$ of metoclopramide. All the injected medications were diluted with normal saline to achieve the total volume of $10 \mathrm{cc}$. The drugs were hidden in pockets specified by numbers were identifiable just for the technicians of anesthesiology in the operative room. Not only patients, but also the researchers and nurses and other technicians measuring the nausea/vomiting were aware of the treatment allocated to each group.

Nausea/vomiting was evaluated at several stages, including before umbilical cord clamping (injection of the drugs) until the end of the operation, as well as post-operation every $6 \mathrm{~h}$ until $24 \mathrm{~h}$ through direct observation by technicians and nurses and also asking from the patient. $\mathrm{SPO}_{2}$ and systolic/diastolic blood pressure were also measured during these times.

\section{Statistical analysis}

All data analysis was performed using SPSS version 21 software. The frequency rates of nausea and vomiting in both groups were measured at different times and compared with the baseline measure using McNemar's test. The early antiemetic efficacy of ondansetron during consecutive times was evaluated using generalized estimating equation model, after controlling for confounding variables such as $\mathrm{SpO}_{2}$.

\section{Results}

The current study was conducted among 120 pregnant women divided into two groups of ondansetron and metoclopramide. The mean \pm SD ages of the ondansetron and metoclopramide groups were $30.1 \pm 6.65$ and $30.71 \pm 9.56 \mathrm{y}$, respectively. The mean \pm SD weights of the ondansetron and metoclopramide groups were $69.86 \pm 12.50$ and $71.21 \pm 12.40 \mathrm{~kg}$, respectively, indicating that the two groups were weight-matched.

Table 1. Quantitative measures in the ondansetron and metoclopramide groups.

\begin{tabular}{|c|c|c|c|c|c|}
\hline \multirow{2}{*}{ Variable } & \multicolumn{2}{|c|}{ Ondansetron group } & \multicolumn{2}{|c|}{$\begin{array}{l}\text { Metoclopramid } \\
\text { e }\end{array}$} & \multirow[t]{2}{*}{ P-value } \\
\hline & Mean & SD & Mean & SD & \\
\hline Age & 30.1 & 6.65 & 30.72 & 9.58 & 0.81 \\
\hline Weight & 69.87 & 12.5 & 71.22 & 12.38 & 0.52 \\
\hline Systolic blood pressure- 0 & 117.58 & 15.96 & 116.25 & 13.49 & 0.33 \\
\hline Systolic blood pressure- 6 & 114.25 & 15.59 & 117.92 & 12.15 & 0.15 \\
\hline Systolic blood pressure-12 & 113.25 & 14.55 & 114.67 & 14.11 & 0.65 \\
\hline Systolic blood pressure-24 & 113.17 & 13.56 & 111.67 & 14.52 & 0.52 \\
\hline Diastolic blood pressure-0 & 75.28 & 9.04 & 74.92 & 9.23 & 0.8 \\
\hline Diastolic blood pressure- 6 & 75.13 & 9.06 & 75.5 & 8.67 & 0.82 \\
\hline
\end{tabular}



cesarean section

\begin{tabular}{|c|c|c|c|c|c|c|}
\hline $\begin{array}{l}\text { Diastolic } \\
\text { pressure-12 }\end{array}$ & blood & 74.03 & 10.21 & 74.33 & 10.23 & 0.92 \\
\hline $\begin{array}{l}\text { Diastolic } \\
\text { pressure-24 }\end{array}$ & blood & 74.35 & 10.04 & 73.92 & 9.7 & 0.87 \\
\hline $\mathrm{SpO}_{2}-0$ & & 91.23 & 1.66 & 90.93 & 0.94 & 0.04 \\
\hline $\mathrm{SpO}_{2}-6$ & & 91.65 & 1.25 & 92.15 & 1.42 & 0.03 \\
\hline $\mathrm{SpO}_{2}-12$ & & 91.63 & 1.97 & 92.4 & 2.03 & 0.11 \\
\hline $\mathrm{SpO}_{2}-24$ & & 92.47 & 1.59 & 92 & 2.52 & 0.11 \\
\hline
\end{tabular}

and $24 \mathrm{~h}(\mathrm{P}<0.001)$ after the operation, frequency of mild nausea and vomiting requiring medical treatment significantly diminished compared to the operation time. Additionally, in the metoclopramide group, frequency of nausea and vomiting requiring medical treatment significantly decreased at 6 $(\mathrm{P}=0.045), 12(\mathrm{P}=0.03)$, and $24 \mathrm{~h}(\mathrm{P}=0.002)$ post-operation, compared to the time immediately after the operation. Between groups comparisons showed no significant differences between metoclopramide and ondansetron regarding nausea/vomiting frequency in each time after the operation.

Means of the quantitative variables are presented in Table 1; as can be noted, only $\mathrm{SpO}_{2}$ was significantly different between the two groups at 0 and $6 \mathrm{~h}$ after the operation.

Table 2 demonstrates that, in the ondansetron group, frequency of nausea and vomiting sensitive to treatment 6 hours after the operation was not significantly different from the stage immediately after the operation $(\mathrm{P}=0.32)$, while $12(\mathrm{P}=0.0005)$

Our initial evaluations showed that the two groups were different in terms of $\mathrm{SpO}_{2}$ at times 0 and $6 \mathrm{~h}$. Accordingly, comparison of the effects of the drugs between the two groups was performed controlling the effects of this variable.

Finally Table 3 shows that the crude and adjusted odds ratios for the antiemetic effect of ondansetron were $0.61(\mathrm{p}=0.23)$ and $0.61(\mathrm{p}=0.19)$ respectively.

Table 2. Comparison of frequency of nausea/vomiting at different times between the ondansetron and metoclopramide groups.

\begin{tabular}{|c|c|c|c|c|c|c|c|c|c|c|c|c|}
\hline \multirow{2}{*}{ Treatment groups } & & \multicolumn{2}{|c|}{$\begin{array}{l}\text { Immediately } \\
\text { operation }\end{array}$} & \multicolumn{3}{|c|}{$6 \mathrm{~h}$ after operation } & \multicolumn{3}{|c|}{$12 \mathrm{~h}$ after operation } & \multicolumn{3}{|c|}{$24 \mathrm{~h}$ after operation } \\
\hline & & $\begin{array}{l}\text { Without } \\
\text { N/V }\end{array}$ & With N/V & $\begin{array}{l}\text { Without } \\
\text { N/V }\end{array}$ & $\begin{array}{l}\text { With } \\
\text { N/V }\end{array}$ & P value $^{*}$ & $\begin{array}{l}\text { Without } \\
\text { N/V }\end{array}$ & With N/V & p value ${ }^{*}$ & $\begin{array}{l}\text { Without } \\
\text { N/V }\end{array}$ & $\begin{array}{l}\text { With } \\
\text { N/V }\end{array}$ & P value ${ }^{*}$ \\
\hline \multirow{2}{*}{ Ondansetron } & No & 38 & 22 & 39 & 21 & 0.32 & 50 & 10 & 0.0005 & 58 & 2 & $<0.001$ \\
\hline & $\%$ & 63.33 & 36.67 & 65 & 35 & & 83.33 & 16.67 & & 96.67 & 3.33 & \\
\hline \multirow{2}{*}{ Metoclopramide } & No & 43 & 17 & 47 & 13 & 0.045 & 49 & 11 & 0.03 & 54 & 6 & 0.002 \\
\hline & $\%$ & 71.67 & 28.33 & 78.33 & 21.67 & & 81.67 & 18.33 & & 90 & 10 & \\
\hline$P$ value ${ }^{* *}$ & & 0.33 & & 0.1 & & & 0.81 & & & 0.27 & & \\
\hline
\end{tabular}

N/V: Nausea/Vomiting; "McNemar test (comparing with time zero); ${ }^{* *}$ Chi square test.

Table 3. The odds ratio of incidence of nausea and vomiting in patients receiving ondansetron to those receiving metoclopramide.

\begin{tabular}{|c|c|c|c|c|}
\hline Treatment & Crude OR (P-value) & $95 \%$ confidence interval & Adjusted OR (P-value) & $95 \%$ confidence interval \\
\hline Ondansetron & $0.61(0.23)$ & $1.37-0.27$ & $0.19(0.61)$ & $0.29-1.28$ \\
\hline Metoclopramide & 1 & & 1 & \\
\hline
\end{tabular}

*Controlling for the effect of $\mathrm{SpO}_{2}$ at 0 and $6 \mathrm{~h}$.

\section{Discussion}

Out results indicated that the rate of nausea and vomiting after injection of ondansetron and metoclopramide significantly declined; nonetheless, the two groups were not significantly different.

It is worth mentioning that comparison of frequency of nausea/ vomiting irrespective of it severity demonstrates the similarity of the two groups at all the time points. Both ondansetron and metoclopramide diminished the frequency of nausea and vomiting, and the reducing effects of both medications were analogous.
On the other hand, we found that prescription of ondansetron could reduce the frequency of nausea and vomiting $40 \%$ more than metoclopramide, but this difference was not statistically significant; therefore, it cannot be generalized to the general population. This result is in line with those of García-Miguel. In their study, metoclopramide and ondansetron significantly lowered the rate of nausea and vomiting compared to the placebo group, but there was no significant difference between ondansetron and metoclopramide groups in this regard [15].

Furthermore, the results of a study by Zahedi et al. were also congruent with our findings. They reported that nausea and vomiting did not occur in $91.8 \%$ and $91.6 \%$ of the patients in ondansetron and metoclopramide groups, respectively, and the two groups were not significantly different [9]. 
In contrast, in a study by Pan et al., frequency rates of intraoperative nausea in ondansetron, metoclopramide, and placebo groups were $24 \%, 43 \%$, and $57 \%$, respectively, while these rates were $26 \%, 51 \%$, and $71 \% 24 \mathrm{~h}$ post-operation, respectively, indicating a significant difference between the two time points. Moreover, in their study, frequency rates of intra and postoperative nausea were similar between the ondansetron and metoclopramide groups, but it was significantly higher in placebo group. They concluded that ondansetron was more effective in controlling nausea in women undergoing cesarean section compared to metoclopramide, and patient satisfaction was higher with ondansetron [14].

Such differences in the results of the above studies can be due to different methodologies of these studies and various definitions of nausea/vomiting. It also might be due to different methods of drug administration.

\section{Conclusion}

It seems that both metoclopramide and ondansetron had similar antiemetic effect. To confirm our findings, conducting longitudinal multi-center studies with larger sample sizes are recommended.

\section{References}

1. Jabalameli M. Treatment of postoperative nausea and vomiting after spinal anesthesia for cesarean delivery: A randomized, double-blinded comparison of midazolam, ondansetron, and a combination. Advanced Biomed Res 2012; $1: 2$.

2. Korttila K. Randomized comparison of recovery after propofol-nitrous oxide versus thiopentone-isofluranenitrous oxide anaesthesia in patients undergoing ambulatory surgery. Acta Anaesthesiologica Scandinavica 1990; 34: 400-403.

3. Meridy HW. Criteria for selection of ambulatory surgical patients and guidelines for anesthetic management: a retrospective study of 1553 cases. Anesth Analgesia 1982; 61: 921-926.

4. Grover V, Mathew P, Hegde H. Efficacy of orally disintegrating ondansetron in preventing postoperative nausea and vomiting after laparoscopic cholecystectomy: a randomised, double-blind placebo controlled study. Anaesthesia 2009; 64: 595-600.

5. Wang J. Dexamethasone reduces nausea and vomiting after laparoscopic cholecystectomy. Brit J Anaesth 1999; 83: 772-775.

6. Katzung BG, Masters SB, Trevor AJ. Basic and clinical pharmacology 12/E inkling (Enhanced Ebook). McGraw Hill Professional 2012.
7. Antonetti M. The effects of preoperative rofecoxib, metoclopramide, dexamethasone, and ondansetron on postoperative pain and nausea in patients undergoing elective laparoscopic cholecystectomy. Surg Endoscopy 2007; 21: 1855-1861.

8. Weiner N, Taylor P. Drugs acting at synaptic and neuroeffector junctional sites. Goodman Gilman's Pharmacol Basis Therap, MacMillan Ltd., New York 1985.

9. Zahedi H, Rouzbeh Kargar L. Comparing the prophylaxis effect of Ondansetron and Metoclopramide against intraoperative nausea and vomiting during spinal anesthesia for cesarean section. JBUMS 2004; 6: 32-36.

10. Norouzi A, Jamilian M, Khalili M, Kamali A, Melikof L. Comparison of the effect of oral and intravenous ondansetron on decreasing nausea and vomiting after cesarean section. AMUJ 2013; 16: 100-107.

11. Yazigi A. Prophylactic ondansetron is effective in the treatment of nausea and vomiting but not on pruritus after cesarean delivery with intrathecal sufentanil-morphine. J Clin Anesth 2002; 14: 183-186.

12. Shende D, Mandal N. Efficacy of ondansetron and metoclopramide for preventing postoperative emesis following strabismus surgery in children. Anaesthesia 1997; 52: 496-500.

13. Suwannarurk L. Comparison between dexamethasone, metoclopramide or ondansetron for the prevention nausea and vomiting following intrathecal morphine for cesarean section. Thammasat Med J 2010; 9: 242-250.

14. Pan PH, Moore CH. Comparing the efficacy of prophylactic metoclopramide, ondansetron, and placebo in cesarean section patients given epidural anesthesia. J Clin Anesth 2001; 13: 430-435.

15. García-Miguel F, Montaño E, Mart V, Fuentes A, Alsina F, San José J. Prophylaxis against intraoperative nausea and vomiting during spinal anesthesia for cesarean section: A comparative study of ondansetron versus metoclopramide. Internet J Anesthesiol 1999; 4: 1-6.

\section{*Correspondence to}

Mahdi Afshari

Department of Community Medicine

Zabol University of Medical Sciences

Zabol

Iran 